\title{
MEEUOVISNOST POSLOVNOG REZULTATA I POKAZATELJA LIKVIDNOSTI HRVATSKIH PODUZEĆA IZ PREHRAMBENE DJELATNOSTI
}

\section{Slobodanka Stjepanović ${ }^{1}$ Melita Cita $^{2}$}

${ }^{1}$ Ekonomski fakultet u Osijeku, Trg Ljudevita Gaja 7,

Osijek, Hrvatska

2 Veleučilište VERN',

Trg bana Josipa Jelačića 3,

Zagreb, Hrvatska

\begin{abstract}
Apstrakt:
U poslovnom odlučivanju značajnu ulogu ima poslovni rezultat koji govori o uspješnosti poslovanja poduzeća te pokazatelji likvidnosti koji ukazuju na sigurnost poslovanja. Prema makroekonomskim pokazateljima za 2015. godinu poduzeća iz prerađivačke djelatnosti imaju važan utjecaj na ukupno gospodarstvo Hrvatske jer ostvaruju najveći udjel u ukupnoj dobiti razdoblja, a 26,85\% svih zaposlenih radi u prerađivačkoj industriji. Kako prehrambena industrija predstavlja glavni sektor u okviru hrvatske prerađivačke industrije gdje je zaposleno oko $20 \%$ svih zaposlenih u prerađivačkoj industriji i koja je izvozno orijentirana, u radu se želi analizirati povezanost poslovnog rezultata $i$ pokazatelja likvidnosti u tim poduzećima.
\end{abstract}

Ključne reči:

poslovni rezultat, likvidnost, Republika Hrvatska, prehrambena industrija.
Korespondencija:

Slobodanka Stjepanović

e-mail:

sstjepa@efos.hr
UVOD

Poduzeća su u svom svakodnevnom poslovanju izložena mnogobrojnim rizicima, među kojima je i rizik nelikvidnosti, odnosno likvidnosti. Rizik likvidnosti je dugo bio podcijenjen, pretpostavka je da vješto upravljanje likvidnosti utječe i na poslovni uspjeh poduzeća. Vremenom su se razvili mnogobrojni financijski pokazatelji uspješnosti poslovanja, kao rezultat mnogobrojnih istraživanja uspješnosti poduzeća. Može se reći kako ne postoji jedan pokazatelj mjerenja uspješnosti poslovanja, već čitav niz pokazatelja ovisno s kojeg stajališta se promatra uspješnost. Pokazatelji likvidnosti predstavljaju jedne od mnogobrojnih pokazatelja uspješnosti poslovanja, a zasnovani su na podacima iz bilance poduzeća. Budući da se veličina ostvarene dobiti iščitava iz računa dobiti i gubitka, a pokazatelji likvidnosti izračunavaju na osnovi podataka iskazanih u bilanci poduzeća ovime će se povezati ova dva temeljna financijska izvještaja.

U radu je analiziran uzorak od 31 velikog poduzeća u grani djelatnosti prerađivačka industrija - prehrambena industrija u petogodišnjem razdoblju 2011. - 2015. godine na način da se promatrala povezanost ostvarenog poslovnog rezultata poduzeća mjerenog kroz ostvarenu dobit sa pokazateljima likvidnosti. Cilj ovog rada je utvrditi stupanj i smjer povezanosti između predmetnih pokazatelja. Na temelju postavljenog cilja i predmeta istraživanja postavljeno je sljedeće istraživačko pitanje: Postoji li pozitivna korelacija između pokazatelja neto dobiti i pokazatelja likvidnosti poduzeća iz djelatnosti prerađivačka industrija - prehrambena industrija? Pretpostavlja se da postoji povezanost između neto dobiti i likvidnosti kod poduzeća i da ta povezanost ima pozitivan predznak, odnosno da veća profitabilnost podrazumijeva veću likvidnost, i obrnuto. U empirijskom dijelu rada pokušat će se odgovoriti na navedeno istraživačko pitanje.

Rad je strukturiran na način da su nakon uvoda u prvom poglavlju iznesene teorijske postavke, u drugom poglavlju definiran uzorak i metodologija istraživanja, dok su u trećem poglavlju dati rezultati istraživanja. Zaključno poglavlje sintetizira dobivene rezultate i daje preporuke za daljnja istraživanja. 


\section{TEORIJSKE POSTAVKE}

Uspješnost poslovanja poduzeća se može pratiti s različitih stajališta npr. ekonomskog, pravnog, tehničkog i sl., što rezultira mnoštvom pokazatelja bilo kvantitativnih ili pak kvalitativnih. S ekonomskog stajališta može se smatrati da je poduzeće uspješno poslovalo ukoliko je ostvarilo ekonomski uspjeh. U radu je orijentacija na kvantitativne pokazatelje s ekonomskog stajališta. Uspješnost poslovanja pratit će se kroz kretanje ostvarenog poslovnog rezultata, a jedan od osnovnih pokazatelja je visina ostvarene dobiti kao mjera profitabilnosti. Ostvarena dobit iščitava se iz računa dobiti i gubitka i predstavlja apsolutnu mjeru koja se uspoređuje s ostvarenom vrijednosti bilo konkurencije, odnosno djelatnosti u kojoj poduzeće djeluje, bilo s povijesnim pokazateljima poduzeća, tj. vrijednostima ostvarenim u prethodnom razdoblju ili pak s planiranim veličinama jer prava vrijednost financijskih pokazatelja dolazi do izražaja tek komparativnom analizom kako bi se procijenila uspješnost poslovanja. Naime, visina ostvarene dobiti sama po sebi malo će značiti ukoliko se ne usporedi npr. s ostvarenim rezultatima prethodnog razdoblja, plana ili pak glavnih konkurenata kako bi se spoznalo ostvarenje zacrtanih ciljeva odnosno definirala pozicioniranost poduzeća na tržištu.

Iako poduzeće iskazuje dobit u svojim financijskim izvještajima, njegova uspješnost poslovanja ovisiti će i o njegovoj sposobnosti i mogućnostima podmirenja obveza prema dobavljačima, kreditorima, zaposlenicima, državi i sl. tako da su od velikog značaja ostvareni pokazatelji likvidnosti. Pokazatelji likvidnosti se iskazuju sučeljavanjem podataka o ostvarenoj kratkoročnoj imovini i kratkoročnim obvezama iskazanim u bilanci poduzeća. U svrhu cjelovite spoznaje o uspješnosti poslovanja ostvarena dobit, pokazatelj koji se iščitava iz računa dobiti i gubitka, povezati će se s pokazateljima likvidnosti zasnovanih na podacima iz bilance poduzeća. Prilikom izračuna ovih pokazatelja treba voditi računa i o rizicima u pogledu točnosti vrednovanja pojedinih pozicija koje se koriste u izračunu pokazatelja kako likvidnosti tako i financijskog rezultata, a što se posebice odnosi na potraživanja i zalihe.

Kao pokazatelji likvidnosti iskazuju se:

- pokazatelj trenutne likvidnosti,

- pokazatelj tekuće likvidnosti,

- pokazatelj ubrzane likvidnosti.

Definiranje pojma likvidnost moguće je na različite načine, tako npr. Orsag (2011, str. 117) kaže: „Ako se likvidnost shvati u izvornom obliku kao sposobnost cirkulacije imovine u kružnom toku poslovnih procesa poduzeća u planiranom obujmu i planiranom dinamikom, onda je ona i pretpostavka takvog poslovanja privrednog subjekta. Na taj se način likvidnost poslovanja može označiti sposobnošću odvijanja poslovanja bez zastoja, kroz slobodnu cirkulaciju imovine u poslovnim procesima bez zastoja." Belak (2014, str.130) je sasvim pojednostavio definiciju likvidnosti: "Likvidnost se može definirati kao sposobnost plaćanja tekućih obveza." Odnosno, likvidnost se često shvaća kao sposobnost imovine, ili pak pojedinih dijelova imovine, da se lako i u što kraćem razdoblju mogu pretvoriti u novčani oblik dovoljan za podmirenje preuzetih obveza, te u tom smislu može se reći da se radi o likvidnosti imovine, a ne likvidnosti poslovanja. Kako bi se omogućilo nesmetano odvijanje poslovanja i izbjegli rizici nemogućnosti podmirenja obveza, a time i mogućnosti pravovremenog snabdijevanja poslovnog ciklusa potrebnim inputima, poduzeća teže očuvanju likvidnosti.

Pokazatelj trenutne likvidnosti (Cash Ratio) izračunava se stavljanjem u odnos novčanih sredstava i kratkoročnih obveza.

Trenutna likvidnost $=$ novac $/$ kratkoročne obveze

Pokazatelj trenutne likvidnosti pokazuje koliki dio kratkoročnih obveza može biti trenutno pokriveno, odnosno plaćeno gotovinom. Značajan je u situaciji kada potraživanja čine pretežiti dio kratkotrajne imovine, a pri tome su još prisutni i problemi u naplati potraživanja, odnosno kašnjenje naplate. Ovaj pokazatelj se smatra prilično nestabilnim i može biti koristan kao informacija da račun nije blokiran. U praksi se najčešće smatra kako ne postoji kontrolna mjera ovog pokazatelja, iako neki smatraju kako ovaj koeficijent ne bi trebao biti manji od 0,10, odnosno 10\% (Vukojević \& Balen, 2006, str. 41).

Pokazatelj tekuće likvidnosti (Current Ratio) se zasniva na odnosu kratkotrajne imovine i kratkoročnih obveza, odnosno mjeri kolika je sposobnost poduzeća da iz kratkotrajne imovine podmiri svoje kratkoročne obveze.

\section{Tekuća likvidnost $=$ kratkotrajna imovina $/$ kratkoročne} obveze

Poželjno je da je ovaj pokazatelj veći ili jednak dva, odnosno da je odnos kratkotrajne imovine i kratkoročnih obveza približno 2:1. U svakom slučaju poželjno je ovaj pokazatelj usporediti s pokazateljem poduzeća iste grane djelatnosti te ukoliko je manji od 1,5 to ukazuje kako postoji mogućnost nedostatka sredstava za podmirenje obveza. „U teoriji nailazimo da je idealna vrijednost ovog pokazatelja 2,00, dok se kritična vrijednost smatra ako je koeficijent manji od 1,00, a upitna likvidnost ako je granična vrijednost 1,00 do 2,00“. (Ramljak, 2011, str. 8).

Pokazatelj ubrzane likvidnosti (Quick Ratio) ili „kiseli“ test (Acid Test) zasniva se na odnosu kratkotrajne imovine koja je umanjena za vrijednost zaliha i kratkoročnih obveza.

Ubrzana likvidnost $=($ kratkotrajna imovina - zalihe $) /$ kratkoročne obveze 
Smatra se da kratkoročne obveze ne bi smjele premašiti iznos kratkotrajne imovine umanjene za zalihe. Ovaj pokazatelj daje odgovor na pitanje raspolaže li poduzeće s dovoljno kratkoročnih sredstava kako bi podmirilo svoje obveze, a da pri tome ne proda zalihe. "U teoriji nailazimo da idealna vrijednost ovog pokazatelja iznosi 1,00 što znači da će poslovni subjekt biti u stanju udovoljiti na vrijeme svojim tekućim obvezama. Visoka vrijednost znači da je potrebno unaprijediti upravljanje gotovinom radi smanjenja suviška gotovine, pooštriti kreditnu politiku ili smanjiti kratkotrajnu u korist dugotrajne imovine." (Ramljak, 2011, str. 9).

Pretraživanjem domaće i inozemne literature nailazimo da se u većoj mjeri likvidnost promatrala u kontekstu strukture radnog kapitala i njihove povezanosti sa profitabilnošću poduzeća. To je na primjer slučaj kod istraživanja međuovisnosti novčanog jaza i profitabilnosti u hotelskoj industriji u razdoblju od 2009. godine do 2012. godine koje su proveli Tušek et al. (2014, str. 55). „Novčani jaz predstavlja razliku između broja dana prodaje zaliha i naplate potraživanja s jedne strane te broja dana plaćanja obveza dobavljačima s druge strane, stoga se novčani jaz u ovom radu koristi kao mjera likvidnosti." (Tušek et al., 2014, str. 55) Rezultati njihovog istraživanja su pokazali da:

a) ne postoji statistički značajna linearna veza između novčanog jaza i računovodstvene dobiti prije oporezivanja,

b) ne postoji statistički značajna korelacija između novčanog jaza i rentabilnosti imovine te

c) ne postoji statistički značajna korelacija između novčanog jaza i rentabilnosti kapitala." (Tušek et al., 2014, str. 55) Mamić Sačer et al. (2013, str. 15) su istraživali utjecaj likvidnosti na profitabilnost hrvatskih srednjih i velikih poduzeća u grani djelatnosti informacije i komunikacije u razdoblju od 2007. godine do 2009. godine primjenom horizontalne i vertikalne analize, te analizom financijskih pokazatelja, te su utvrdili da „povećanje vrijednosti koeficijenta tekuće likvidnosti utječe na povećanje vrijednosti bruto rentabilnosti imovine."

Sorić (2002, str. 932) je ispitivao povezanost poslovnog rezultata i pokazatelja likvidnosti gospodarstva Splitsko-dalmatinske županije i došao do slijedećeg zaključka: „Niske stope likvidnosti i iskazani neto gubitak ukazali su na postojanje korelacijske negativne veze po kojoj porast gubitka prati istovremeni pad likvidnosti“.

Gabrić (2015) je analizirao povezanost profitabilnosti i likvidnosti kod poduzeća na tržištu kapitala u Federaciji BiH u razdoblju od 2010. godine do 2013. godine. Rezultati ispitivanja pokazali su da „postoji pozitivna povezanost između pokazatelja profitabilnosti i likvidnosti kod promatranih poduzeća u promatranom razdoblju." (Gabrić, 2015, str. 79).

Bhunia et al. (2012) ukazuju na postojanje povezanosti likvidnosti i profitabilnosti na primjeru indijskih poduzeća iz sektora upravljanja robom široke potrošnje.
Istraživanje koje su proveli Bagchi et al. (2012) na primjeru indijskih poduzeća u razdoblju od 2000. do 2010. godine ukazalo je na postojanje negativne korelacije između likvidnosti i rentabilnosti.

\section{PRIKUPLJANJE PODATAKA I METODOLOGIJA ISTRAŽIVANJA}

Prikupljeni podaci odnose se na uzorak poduzeća (trideset i jedno veliko poduzeće) iz Republike Hrvatske te njihovim statističkim podacima o dobiti nakon oporezivanja i pokazateljima tekuće likvidnosti, ubrzane likvidnosti, te pokazatelja trenutne likvidnosti za razdoblje od 2011. do 2015. godine. Radi se o službenim statističkim podacima prikupljenih iz financijskih izvještaja istih gospodarskih subjekata, a koji su objavljeni na stranicama Poslovna.hr.

Navedena poduzeća su iz područja djelatnosti C - prerađivačka industrija, odjeljak 10. Proizvodnja prehrambenih proizvoda - skupina 10.1. do 10.8. (Narodne novine 58/07) i koja su prema Zakonu o računovodstvu (Narodne novine 78/2015, 134/2015) razvrstana kao velika poduzeća. Prilikom ispitivanja i dovođenja u vezu poslovnog rezultata i pokazatelja likvidnosti korištena je regresijska analiza, odnosno Pearsonov koeficijent korelacije.

Poduzeća koja su činila uzorak su sljedeća: Meggle Hrvatska d.o.o., KIM d.o.o., Granolio d.d., Mesna industrija Braća Pivac d.o.o., PPK d.d. Karlovac, Perutnina Ptuj - PIPO d.o.o., PIK Vrbovec - Mesna industrija d.d., Gavrilović d.o.o., Vajda d.d. Čakovec, MM Mesna industrija d.o.o., Sardina d.o.o. Postira, Podravka d.d., Zvijezda d.d., Vindija d.d., Dukat d.d., Ledo d.d., Mlinar d.d., Zagrebačke pekarne Klara d.d., Mlin i pekare d.o.o., Centar Škojo d.o.o., PIK d.d. Rijeka, Koestlin d.d., Karolina d.o.o., Tvornica šécera Osijek d.o.o., Sladorana d.o.o. Županja, Viro Tvornica šećera d.d., Kraš d.d., Kandit d.o.o., Zvečevo d.d., Franck d.d. i Cedevita d.o.o.

Prikupljeni statistički podaci o veličini pokazatelja uspješnosti poslovanja i pokazatelja likvidnosti obrađeni su primjenom modela jednostavne linearne regresije. U modelima je pokazatelj uspješnosti poslovanja promatran kao nezavisna varijabla, a pokazatelji likvidnosti kao zavisne varijable, te su za svaki od pretpostavljenih modela sačinjene jednadžbe pravaca regresije, te je izračunat Pearsonov koeficijent linearne korelacije, koji opisuje smjer i jakost statističke povezanosti između navedenih varijabli.

\section{REZULTATI ISTRAŽIVANJA}

$\mathrm{Na}$ osnovi informacija o ostvarenom poslovnom rezultatu mjerenom kroz neto dobit, te osnovnih pokazatelja likvidnosti velikih hrvatskih poduzeća iz prehrambene djelatnosti za razdoblje od 2011. do 2015., izračunata je prosječna neto dobit te prosječni pokazatelji likvidnosti. U promatranom razdoblju pokazatelj tekuće likvidnosti je bio oko 1,5 što se 
smatra nezadovoljavajućim, budući da je poželjno da je on dva ili veći od dva. Prosječni pokazatelj ubrzane likvidnosti iznosio je 1,02, dok je prosječna vrijednost pokazatelja trenutne likvidnosti 0,05. Pearsonov koeficijent linearne korelacije između neto dobiti i pokazatelja tekuće likvidnosti iznosi 0,92 i negativnog je predznaka, što ukazuje na postojanje relativno jake negativne veze između tih veličina; kao i kod Pearsonovog koeficijenta između neto dobiti i pokazatelja ubrzane likvidnosti gdje iznosi 0,87 i također je negativnog predznaka. Kod istraživanja međuovisnosti između neto dobiti i pokazatelja trenutne likvidnosti Pearsonov koeficijent iznosi 0,412 te odražava veoma nisku pozitivnu vezu. Visoka razina Pearsonovog koeficijenta kod tekuće i ubrzane likvidnosti mogu se objasniti podacima koji idu u brojnik formule za izračun istih stopa likvidnosti (novac, potraživanja, zalihe, financijska imovina). Na primjer, kod nekih poduzeća iz uzorka pokazatelj likvidnosti je manji od 2, a pokazatelj ubrzane likvidnosti veći od 1 što ukazuje da se loše upravlja zalihama (visok iznos zaliha) kao što je npr. slučaj sa Meggleom (u 2015. godini koeficijent likvidnosti iznosi 1,34, a koeficijent ubrzane likvidnosti 1,15). Ili npr. visok koeficijent likvidnosti u 2014. godini kod Leda d.d. je iznosio 6,46 što potencijalno ukazuje na probleme sa prekomjernim zalihama, visokim nenaplaćenim potraživanjima i visokim iznosima kratkotrajne financijske imovine.

Kako su navedena poduzeća iz prerađivačke industrije proizvodnja prehrambenih proizvoda razvrstana u različite skupine prema Nacionalnoj klasifikaciji djelatnosti, u istraživanju se željela također ispitati jakost statističke povezanosti između navedenih varijabli prema određenim skupinama djelatnosti. Prethodno su izračunati pokazatelji tekuće, trenutne i ubrzane likvidnosti, te neto dobiti (neto gubitka) po djelatnostima za navedeno razdoblje. Sva navedena poduzeća, gledajući u promatranom razdoblju, ostvarila su prosječnu neto dobit, osim poduzeća koja su razvrstana u skupine 10.72. i 10.82., odnosno koja se bave proizvodnjom dvopeka, keksa i srodnih proizvoda (Karolina d.o.o., Koestlin d.d.), te proizvodnjom kakao, čokoladnih i bombonskih proizvoda (Kraš d.d., Kandit d.d., Zvečevo d.d.) koja su iskazala prosječni gubitak.

Idealna vrijednost pokazatelja tekuće likvidnosti iznosi 2,00 i taj pokazatelj ostvarila su poduzeća iz djelatnosti prerade i konzerviranja voća, te proizvodnje biljnih i životinjskih masti (Podravka d.d. i Zvijezda d.d.) i iznosi 2,21. Većina poduzeća u ostalim djelatnostima prerađivačke industrije imaju pokazatelj oko 1,5 (tablica 2). Jedino poduzeća iz razreda 10.61. i 10.71. odnosno proizvodnja mlinskih proizvoda, te proizvodnja kruha, svježih peciva imaju kritičnu vrijednost navedenog pokazatelja koja iznosi 0,99. U navedenom razdoblju najlošiji pokazatelj ubrzane likvidnosti imala su poduzeća koja se bave proizvodnjom šećera $(-0,55)$ i proizvodnjom mlinskih proizvoda $(-0,71)$. Pokazatelj trenutne likvidnosti je bio najlošiji kod poduzeća koja se bave proizvodnjom mlinskih proizvoda i proizvodnjom kruha: Granolio d.d., Mlinar d.d., Zagrebačke pekarne Klara d.d., PIK d.d., Mlin i pekare d.o.o., Centar Škojo d.o.o. i iznosio je 0,03.
Na temelju dobivene vrijednosti Pearsonovog koeficijenta može se zaključiti da postoji relativno jaka pozitivna veza između neto dobiti i pokazatelja tekuće likvidnosti $(0,97)$, neto dobiti i pokazatelja ubrzane likvidnosti $(0,97)$, te neto dobiti i trenutne likvidnosti $(0,99)$ kod poduzeća koja se bave preradom i konzerviranjem voća.

Pozitivna vrijednost Pearsonovog koeficijenta linearne korelacije između neto dobiti i pokazatelja tekuće i ubrzane likvidnosti kod poduzeća koja se bave proizvodnjom šećera ukazuje na njihovu jaku pozitivnu povezanost ( 0,88 odnosno $0,98)$. Srednje jaku pozitivnu povezanost između neto dobiti i pokazatelja likvidnosti imamo kod poduzeća iz djelatnosti skupine 10.83. i 10.86., odnosno prerade čaja i kave, proizvodnja homogeniziranih prehrambenih pripravaka (Franck d.d. i Cedevita d.o.o.) koja kod tekuće likvidnosti iznosi 0,65, kod ubrzane likvidnosti 0,68 i trenutne likvidnosti 0,66. Pozitivna vrijednost koeficijenta ukazuje da rast dobiti utječe na rast likvidnosti i obrnuto. Kod poduzeća iz djelatnosti mlinskih proizvoda i proizvodnje kruha, kao i kod poduzeća koja se bave preradom i proizvodnjom mesnih proizvoda i preradom ribe, postoji srednje jaka negativna povezanost između neto dobiti i pokazatelja tekuće i ubrzane likvidnosti, odnosno rast dobiti utječe na pad pokazatelja likvidnosti i obrnuto. Istraživanje je pokazalo da postoji slaba pozitivna vrijednost koeficijenta linearne korelacije između neto gubitka i pokazatelja tekuće i ubrzane likvidnosti kod poduzeća iz djelatnosti iz skupine 10.72. i 10.82. Na temelju dobivene vrijednosti Pearsonovog koeficijenta korelacije između neto dobiti i pokazatelja ubrzane likvidnosti kod poduzeća koja se bave proizvodnjom mliječnih proizvoda (djelatnosti mljekara i proizvođača sira, te proizvodnja sladoleda), može se zaključiti da postoji relativno slaba pozitivna veza $(0,49)$ između ostvarene dobiti i pokazatelja ubrzane likvidnosti. Istraživanje je također pokazalo da je jako niska (ili čak nula) vrijednost koeficijenta linearne korelacije između poslovnog rezultata i pokazatelja trenutne likvidnosti (osim kod poduzeća koja su razvrstana u skupine 10.3. i 10.4., kod poduzeća iz skupine 10.61. i 10.71., kao i kod poduzeća iz skupine 10.72. i 10.82.). To proizlazi zbog vremenske nepodudarnosti između prihoda i primitaka, odnosno rashoda i novčanih izdataka (novac na žiro računu je iskazan na dan 31.12.).

\section{ZAKLJUČAK}

Poduzeća su u svom poslovanju izložena mnogobrojnim rizicima. Naime, promjenjivost cijena sirovina, kamatnih stopa, rizik naplate utječu ne samo na uspješnost poslovanja poduzeća i ostvarivanje dobiti za vlasnike već određuju i opstanak poduzeća u poslovnom okruženju. Jedan od značajnih rizika je i rizik likvidnosti. Kako bi se omogućilo pravovremeno snabdijevanje poslovnog ciklusa inputima, potrebno je na vrijeme podmiriti kratkoročne obveze, ali i naplatiti potraživanja. Odnosno, potrebno je manje likvidnu imovinu 
dovoljno brzo prevesti u viši stupanj likvidnosti, sukladno dospjelim obvezama, kako bi se one na vrijeme podmirile. Potrebno je vremenski uskladiti prihode i rashode, potraživanja i obveze. Osnovica izračuna pokazatelja likvidnosti su podaci iz bilance poduzeća i prikazuju samo jedan trenutak stanja imovine i obveza (31.12.), dok se neto dobit iščitava iz računa dobiti i gubitka i rezultat je razlika ostvarenih prihoda i rashoda tijekom kalendarske godine.

$\mathrm{Na}$ temelju dobivenih rezultata korelacijske analize može se negativno odgovoriti na postavljeno istraživačko pitanje: Da li postoji pozitivna korelacija između pokazatelja neto dobiti i pokazatelja likvidnosti poduzeća iz djelatnosti prerađivačka industrija - prehrambena industrija? Naime, ovo istraživanje ukazalo je na značajnu negativnu povezanost ostvarene neto dobiti i pokazatelja tekuće i ubrzane likvidnosti (Pearsonov koeficijent 0,92 i 0,87 ), te vrlo malu povezanost sa pokazateljem trenutne likvidnosti velikih poduzeća iz prehrambene djelatnosti. Dobiveni rezultati su u skladu sa sličnim provedenim istraživanjima npr. Bagchi et al. (2012). Kako su navedena poduzeća razvrstana u različite skupine prema Nacionalnoj klasifikaciji djelatnosti, u istraživanju se željela također ispitati jakost statističke povezanosti između navedenih varijabli prema određenim skupinama djelatnosti. Utvrđeno je da kod poduzeća iz skupine djelatnosti koja ima veći pokazatelj tekuće i ubrzane likvidnosti postoji i veća pozitivna povezanost između pokazatelja likvidnosti i dobiti. Dobiveni rezultati su u skladu sa provedenim sličnim istraživanjima npr. Mamić Sačer et al. (2013) i Bhunia et al. (2012). Potencijalno ograničenje istraživanja je korišćenje prosječnih vrijednosti pokazatelja unutar djelatnosti i cijelog uzorka, jer ono može imati negativne posljedice na pouzdanost rezultata.

Doprinos ovog rada temelji se na proučavanju i analizi povezanosti pokazatelja neto dobiti i likvidnosti poduzeća iz prehrambene industrije u Republici Hrvatskoj u razdoblju od 2011. do 2015. godine. Istraživanje bi trebalo nastaviti i ispitati profitabilnost i likvidnost mjerenih pokazateljima novčanog toka bez uprosječivanja pokazatelja unutar djelatnosti i cijelog uzorka. Ovo istraživanje može biti od koristi menadžerima poduzeća, ali i potencijalnim ulagačima kao informacija koja će im pomoći pri donošenju poslovnih odluka.

\section{LITERATURA}

Bagchi, B., Chakrabarti, J., \& Basy Roy, P. (2012). Influence of Working Capital Management on Profitability: A Study on Indian FMCG Companies. International Jornal of Business and Management, 7(22), 1-10. doi:10.5539/ijbm.v7n22p1

Belak, V. (2014). Analiza poslovne uspješnosti. Zagreb: RRiF-plus d.o.o. za nakladništvo i poslovne usluge.

Bhunia, A., Bagchi, B., \& Khamrui, B. (2012). The Impact of Liquidity on Profitability: A Case Study of FMCG Companies in India. Research and Social practices in Social Sciences, 7(2), 44-58. doi:10.4236/me.2013.410072

Gabrić, D. (2015). Istraživanje povezanosti profitabilnosti i likvidnosti kod poduzeća na tržištu kapitala u Federaciji BiH. 7. Međunarodna naučno - stručna konferencija Business Development Conference (BDC), Razvoj poslovanja 2015 Ekonomska politika i poslovanje malih i srednjih poduzeća, Zenica,13.11.2015. (glavni urednik Alaudin Brkić). Zenica: Ekonomski fakultet Univerziteta u Zenici, str. 79-90.

Mamić Sačer, I., Tušek, B., \& Korica, I. (2013). Empirijska analiza utjecaja likvidnosti na profitabilnost hrvatskih srednjih i velikih poduzeća u grani djelatnosti informacije i komunikacije. Zagreb: Zbornik Ekonomskog fakulteta u Zagrebu, 11(2), 15-35.

Narodne novine. (2007). Zakon o nacionalnoj klasifikaciji. Narodne novine 58/07.

Narodne novine. (2015). Zakon o računovodstvu. Narodne novine 109/07, 78/2015, 134/2015.

Orsag, S. (2011). Vrijednosni papiri: Investicije i instrumenti financiranja. Sarajevo: Revicon.

Poslovna hr. (2015). Financijski pokazatelji. Retrieved Jun 22, 2016 from //http://nova.poslovna.hr/

Ramljak, B. (2011). Korištenje financijskih izvještaja u funkciji razotkrivanja i rješavanja nelikvidnosti poslovnih subjekata. 46. simpozij Hrvatske zajednice računovođa i financijskih djelatnika "Financijske i računovodstvene mjere izlaska iz recesije", Dubrovnik, (05-07.) svibanj 2011. / (glavni urednik Danimir Gulin). Zagreb: Hrvatska zajednica računovođa i financijskih djelatnika, 116-124.

Sorić, I. (2002). Analiza povezanosti između poslovnog rezultata i likvidnosti. Ekonomski pregled, 53(9-10), 921-933.

Tušek, B., Perčević, H., \& Hladika, M. (2014). Međuovisnost novčanog jaza i profitabilnosti u hotelskoj industriji u Republici Hrvatskoj. Acta Turistica, 26(1), 55-75.

Vujević, K., \& Balen, M. (2006). Pokazatelji uspješnosti poslovanja poduzeća pomorskoga prometa. Pomorstvo, 20(2), 33-45.

\section{PRILOG}

Tablica 1. Pearsonov koeficijent neto dobiti financijske godine (u milijunima kuna) i pokazatelja likvidnosti u razdoblju 2011. za prerađivačku industriju - proizvodnja prehrambenih proizvoda

\begin{tabular}{clcccc}
\hline Odjeljak iz NKD & \multicolumn{1}{c}{ Naziv } & $\begin{array}{c}\text { Prosječna } \\
\text { neto dobit u } \\
\text { milijunima kuna. }\end{array}$ & $\begin{array}{c}\text { Prosječna veličina } \\
\text { pokazatelj tekuće } \\
\text { likvidnosti }\end{array}$ & $\begin{array}{c}\text { Prosječna veličina } \\
\text { pokazatelj } \\
\text { ubrzane } \\
\text { likvidnosti }\end{array}$ & $\begin{array}{c}\text { Prosječna veličina } \\
\text { pokazatelj } \\
\text { trenutne } \\
\text { likvidnosti }\end{array}$ \\
\hline \multirow{2}{*}{10} & $\begin{array}{l}\text { Proizvodnja } \\
\text { prehrambenih proizvoda }\end{array}$ & 647,6 & 1,52 & 1,02 & 0,05 \\
\hline & Pearsonov koeficijent & & $-0,92$ & $-0,87$ & $-0,4$ \\
\hline
\end{tabular}

Izvor: Izračun autora na temelju podataka iz Poslovna.hr 
Tablica 2. Pearsonov koeficijent neto dobiti financijske godine (u milijunima kuna) i pokazatelja likvidnosti u razdoblju 2011. - 2015. po skupinama iz nkd.

\begin{tabular}{|c|c|c|c|c|c|}
\hline $\begin{array}{l}\text { Skupina iz } \\
\text { NKD }\end{array}$ & Djelatnost prema skupini & $\begin{array}{l}\text { Prosječna neto } \\
\text { dobit (gubitak) u } \\
\text { mil. kn. }\end{array}$ & $\begin{array}{l}\text { Prosječna veličina } \\
\text { pokazatelj tekuće } \\
\text { likvidnosti }\end{array}$ & $\begin{array}{l}\text { Prosječna veličina } \\
\text { pokazatelj ubr- } \\
\text { zane likvidnosti }\end{array}$ & $\begin{array}{c}\text { Prosječna veličina } \\
\text { pokazatelj tre- } \\
\text { nutne likvidnosti }\end{array}$ \\
\hline \multirow[t]{2}{*}{ 10.1. i 10.2.} & $\begin{array}{l}\text { Prerada i proizvodnja mesnih proizvoda } \\
\text { i prerada riba }\end{array}$ & 825,10 & 1,61 & 0,91 & 0,04 \\
\hline & Pearsonov koeficijent & & 0,566 & 0,69 & 0,043 \\
\hline \multirow[t]{2}{*}{ 10.3. i 10.4} & $\begin{array}{l}\text { Prerada i konzerviranje voća, proizvod- } \\
\text { nja biljnih i životinjskih masti }\end{array}$ & 108,63 & 2,21 & 2,06 & 0,12 \\
\hline & Pearsonov koeficijent & & 0,97 & 0,97 & 0,99 \\
\hline \multirow[t]{2}{*}{10.5} & Proizvodnja mliječnih proizvoda. & 233,91 & 1,57 & 1,46 & 0,07 \\
\hline & Pearsonov koeficijent & & * & 0,49 & 0,06 \\
\hline \multirow[t]{2}{*}{ 10.61. i 10.71 . } & $\begin{array}{l}\text { Proizvodnja mlinskih proizvoda, proiz- } \\
\text { vodnja kruha. }\end{array}$ & 33,12 & 0,99 & 0,71 & 0,03 \\
\hline & Pearsonov koeficijent & & 0,66 & 0,67 & 0,62 \\
\hline \multirow[t]{2}{*}{ 10.72. i 10.82 . } & $\begin{array}{l}\text { Proizvodnja dvopeka, keksa i srod- } \\
\text { nih proizvoda, proizvodnja kakao, } \\
\text { čokoladnih i bombonskih proizvoda }\end{array}$ & $(2,64)$ & 1,4 & 1,07 & 0,05 \\
\hline & Pearsonov koeficijent & & 0,21 & 0,21 & 0,52 \\
\hline \multirow[t]{2}{*}{10.81.} & Proizvodnja šećera & 37,53 & 1,25 & 0,55 & 0,09 \\
\hline & Pearsonov koeficijent & & 0,88 & 0,98 & 0,07 \\
\hline \multirow[t]{2}{*}{ 10.83. i 10.86.} & $\begin{array}{l}\text { Prerada čaja i kave, proizvodnja homog- } \\
\text { eniziranih prehrambenih pripravaka }\end{array}$ & 71,92 & 1,36 & 1,13 & 0,05 \\
\hline & Pearsonov koeficijent & & 0,65 & 0,68 & 0,66 \\
\hline
\end{tabular}

Izvor: Izračun autora na temelju podataka iz Poslovna.hr

\section{CORRELATION BETWEEN OPERATING RESULTS AND LIQUIDITY OF THE CROATIAN FOOD INDUSTRY ENTERPRISES}

\section{Abstract:}

Operating result, which indicates the corporate performance, and the liqudity indicators, which point to the safety of the operations, have an important role in the business decision-making. According to macroeconomic indicators for 2015. manufacturing companies have a significant impact on the Croatian economy since they had the largest share in total revenue for the period and $26.85 \%$ of all employees working in the manufacturing industry. As the food industry is a major part of the Croatian manufacturing sector employing about $20 \%$ of all employees in that export-oriented sector, this study aims to examine the association between business performance and liquidity indicators in these companies.

\section{Keywords:}

operating result, liquidity, Republic of Croatia, food industry. 